\title{
Indonesian Skilled Labor for Japan Labor Market seen as Rational Choice
}

\author{
Herjanti Nursuksmaningtyas Santoso ${ }^{1}$, Kurniawaty Iskandar ${ }^{2}$ \\ \{herjantins@gmail.com¹, daradwipa@yahoo.com ${ }^{2}$ \} \\ Universitas Indonesia, Indonesia ${ }^{1,2}$
}

\begin{abstract}
Global Migration is the effect of globalization, there will be also get along with human movement through labor migration across the world. As Japan facing a shortage on its labor force, they need some labor force for foreign country. It's seen as a good chance for Indonesia Labor Force seen to gain knowledge and increasing skill quality through the Internship Program organized by Sending Organization Sending Organization both Indonesia and Japan who are trained by LPK (Lembaga Pelatihan Kerja) in Indonesia and mostly employed in low skilled job sector. The aim for this study is analyzing on what the motivations seen through Rational Choice Theory of Graduated Students Majored in Japanese Language to join the program and how can cope with the cultural barriers of working condition in Japan. The research conducted by using qualitative method which collected through interview on several informants (who have participated as trainee).
\end{abstract}

Keywords: Global Migration, Internship Program, Rational Choice, Skilled Labor

\section{Introduction}

Global Migration has various impacts on human life. The purpose of human migration is not only caused by civil disturbances as we know that used on refugee's term. However, the purpose of migrants on doing migrate is not economically but there are various aspects that migration can be occurred. Those who are less fortunate want to get a decent life by migrating to a place which are considered to be more profitable for them, and have good life expectancies, which are broadly sought are jobs, high wages and various opportunities.

In the global era, international migration is inevitable, but this phenomenon cannot be seen as an impact of globalization alone, but it is a choice for the world community on their lives to be evolved. It is a major reason for a group of people to move for the sake of lifestyle and specifically to get better jobs and income, so that they voluntarily bringing their live out international migration (not as refugees).

In this era of globalization, it is a result of human movement. The movement of Indonesia's skilled workforce with the Japanese language Bachelor Degree, relying on their abilities in language is a provision and an advantage in getting a better life in Japan.

The Japan Foundation, cultural institution of Japan in 2015 claimed the number of Japanese language learners in Indonesia is the largest in Asia with the number of students reaching 745,125 people. This number is also expected to be increasing along with the development of the economy and investments made by Japan in Indonesia. Development of Japanese language learners also increases the number of institutions on study Japanese Language both in formal and informal institutions in lower and higher education. The increase 
on the number of learners of Japanese language is an advantage for Japan looking for workers who have at least the ability in the field of language, so it is expected that by carried out the program there will be no conflict occurred during the training program.

Japan's population declined in recent years and it affected on various aspects of Japanese society, such as decreasing number of productive workforces which has resulted in Aging Society. It implicated the productive labor numbers, whereas Japan opens another way to advance its economy by opening up opportunities for foreign nationals to work in Japan. This is considered by the Japanese government to be a solution to overcome labor shortages in the productive age. The labor force number in Japan which is in the age range of 15 to 50 years is projected to experience a significant decline, while the number of workforces aged 65 years will increase. It can be considered as ineffective and becomes a social cost as the impact. The Figure below explain how the population in Japan in the future.

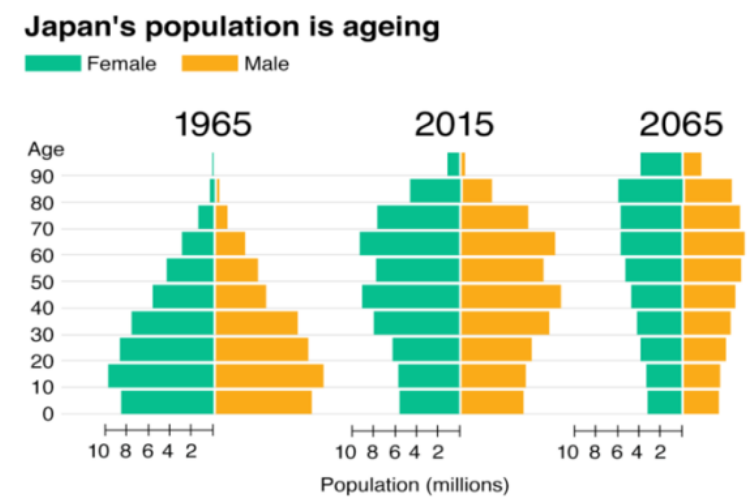

Fig. 1. Japan Aging Population [1].

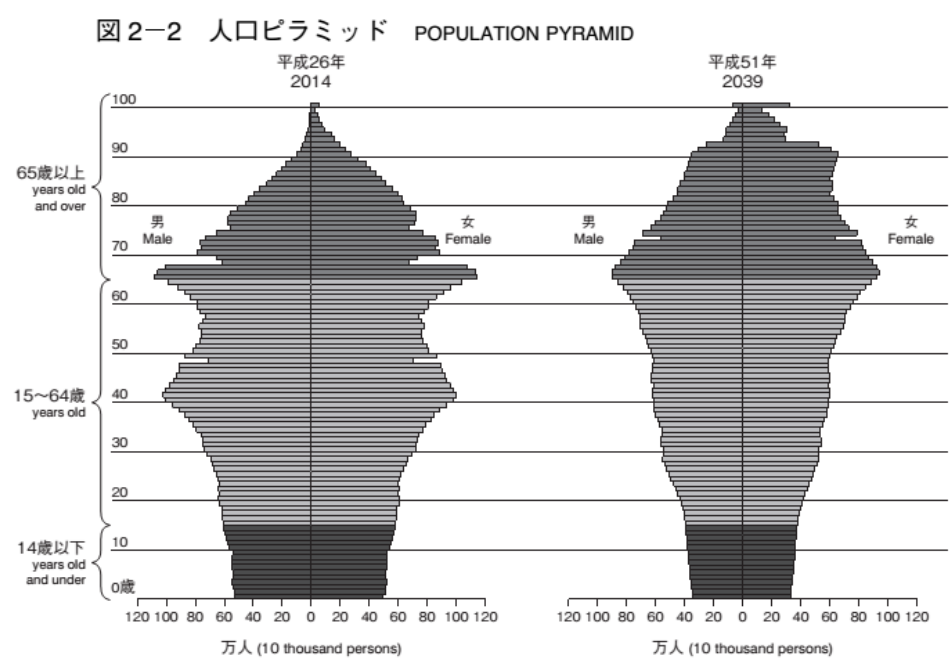

Fig. 2. Population Pyramid [2]. 
The aim of this study is for getting the knowledge what was the motivation of the Bachelor of Japanese Language to be joined the training program and what is the implication of their career after came back to Indonesia.

\section{Methodology}

This research is based on qualitative research with in-depth interview method on several people who has joined the training program majored in Japanese Language Program in University which had come back to Indonesia. Their minimum stayed in Japan. This study use sociology, economic and cultural approaches to get the result about the motivation on joining the training program. The Data that has been collected of this research will be describe by descriptive analysis.

This study examined 3 up to 5 people who has experienced as trainee and had come back in Indonesia. They all graduated from the University majored in Japanese Language. They stayed in Japan for approximately a year up to 3 years. The In-formants having differences socio demographic and cultural background (can be seen by the University, the background of the family and sex). With these various of informant's background will bring more accurate results regarding the Rational Choice of doing the internship program. As this study is still on progressing, snowballing methods will be used in the future, which makes the results in the future broader and more accurate.

The type of this study is qualitative research. Based on the experience and social phenomena that explained by the Informants. The subject of the study is the ex-trainee who had participated on the program for a year until 3 years. Mostly, before they joined the program, they graduated from university majored in Japanese Language and trained by Lembaga Pelatihan Kerja in Indonesia as a Sending Operation.

This conducted by doing interview on several informants whereas the ex-trainee who had graduated from university majored in Japanese Language program. The question that researcher asked about mostly their consideration of joined the internship program in Japan and the experience that they are having while doing the Program.

The Data that have been collected will be delivered in Descriptive Analytic.

\section{Discussion}

This study argue that the rational choice plays the important roles on the actor to decision to join the internship program. Rational Choice stated by Coleman [3] rational action of an individual, as an actor on deciding their action to obtained their purpose by the choices or based on their preferences. Haug [4] using the Rational Choice Theory on her study, decision making on migration of people. Here, she connected how the macro level, meso level and micro level (actor) is related each other on the decision making of migration. To analyze the matter, this study also tries to use the indicator that Haug used. But, as we only examined on actor level as micro level, we analyze the case by using human capital and cultural capital (individual preferences and subjective expectation) on the graduated student from university who joined the training program.

Japan has a good image on several aspects, it's about their technology, economy and their culture. Japan known as a country that has a 'unique' culture and it promoted everywhere. The 
stereotype of Japanese people is known as a people who is diligent, friendly and hard-working. This kind of uniqueness attracted people to travel or stayed longer as worker, trainee or student in Japanese University. The results of the survey that conducted by pewresearch.com (2015) were in Asia-Pacific Area, Japan seen as the country that preferable than the other country in Asia-Pacific area, such as China, South Korea and lastly, the India who has joined the force as economically developed country. As Asia-Pacific Area, most of the country has incredible development on the economic and geopolitics activity.

The good image on Japan, also brought to increasing the tourism sector. The increasing of foreign tourist was increasing each year. The promotion that did by government and business sectoral have an impact. If we take a look on advertisement or Japanese television commercial break, they promoting how beautiful and there are many places to visit in Japan. Kaneko [5] also said the impact of huge promotion is also helped by the Japanese-style Tourism. Japanese Style Tourism use the mascots to attract more people, usually the mascots are called yurukyara which mean gentle and cuddly mascots. The use of this mascots is to attract people to have fun on local event or to promote the city as well.

Japan's Tourism Industry did pretty well. The amount of foreign people came to Japan and it's increasing significantly from 2010 until 2017. In Japan's Statistical Yearbook 2018 noted that there are increasing number of people come to Japan in 2010 from all over the world, from 8 million people to 28 million people in 2017. Approximately, 10 million people come to Japan for traveling. Chinese Tourist is dominated this amount.

The beautiful scenery of Japan and cultural attraction from Japan can bring more foreign people to come to Japan. The same survey that pewresearch.org (2019) informed that the foreign who lives in Japan, feels like don't want to differentiate from the Japanese. We assume that one of the reasons why they are migrated because they want to live like Japanese Style way of live, with the practically of life such as in their technology in their transportation and the use of robots in their daily life. One of Informant said so, she told us she likes living in Japan because its quiet and everything is practical.

Japan itself experienced the lack of labor in low skilled sector, thus it's also caused by the low fertility rate. Japanese young generation that well educated tend to avoid the low-skilled job sector, they look for a better job in Tokyo, for example. So that, the human resource on the suburban area could lack of labor because its low wage. For solving the problems here, using their 'self-branding' as the good and technologically well-built nation, Japan offered the trainee program for the people in development country, including Indonesia.

Indonesia is the fourth country that has a big population all over the world, after China, USA and India. The amount of young people who are productively as a labor per 2017 is about 128 million people at the age of 15 until 65-year-old. Thus, there are an increase on the number of labors, but the unemployment rate of educated labor who graduated from the university is quite high and it's increasing every year. From 2015 about 565 thousand people who graduated from university are unemployed until 2017 reach about 789 thousand people. It means that the number of labors is increasing and unemployment rate also. The well-educated people said lack of skill and the qualification is unmatched with the field of labor. Therefore, is also the push factor our well-educated labor goes to abroad for looking on a better life and chance.

Based on Japan Statistical Yearbook 2018 data the number of Indonesian citizens based on residence permits on medium-term, long-term and special permanent residence lengths which collected from the Immigration Control and Refugee Recognition Act of Japan from 2014 to 2016, has increased quite significant. Starting in 2014 there were 30,210 people, in 2015 there were 35,910 and the last in 2016 increased by 42,850 . As the data said, there will be several people who came to Japan as a trainee or worker. 
The push and pull factor delivered above would be explained by using the rational choice theory in the micro level, the graduated student from university majored in Japanese Language and Literature. The basic assumption that researchers propose is that Japanese graduates do migration by taking part in job training programs in Japan as a form of lifestyle change and to get some benefits including income and better jobs after their come back to Indonesia. As Japanese Language ability is a requirement to conduct an internship program in Japan, they will do that, because there is an opportunity to work and they have tools to do the work, such as the Japanese language skill which they also have a way better understanding in about Japanese traditions and culture.

The motivation will trace by using rational choice theory from Coleman [3], where motivation can be influenced by a rational choice in carrying out an action that can contribute to social change towards itself and its surroundings. By looking at their rational choices, it can be seen also their purpose to take part in job training programs in Japan even though in reality they are employed in unskilled jobs. We analyze what rational choice that they take on decision making to join the program.

The graduated students having a knowledge about the Japanese Language as they experienced as Japanese Language Students. They obtained minimal N3 Level of JLPT (Japanese Language Proficiency Test). It counted that they are in intermediate terms on understanding the language for daily basics and to do the jobs. But unfortunately, the Jobs that them took are unskilled job. Most of the informants work as packaging operator in factory. They pack the product into the boxes and packaging, it's not much required the ability on language to pack something in the boxes. But they required to be nimble and highly concentrated, moreover they must be physically strong because they have to stand 8 during 8 hours working time. They divided on 2 time of working, at night and a day.

The Human capital that they obtained after they studied Japanese in the university is main capital that they brought on the decision making of migration. The other factors that can affected on their decision also is on the cultural capital, we divided on their individual preferences and their subjective expectations that they acquired on this internship program. The Individual Preferences on mostly about their consideration on living abroad and duration of staying with other consequences that they must face.

First, Individual Preferences to choose the company, two informants said they considering about the privilege on doing the Internship is preferred because they can do the religion practice during their work time in Japan. The company that employed them provide the place for praying and having them to wear a hijab as a Moslem. The informants said that they wouldn't do the internship if they didn't have this privilege. As we know, Japan has the tight working hour and they are not in religion practical like in Islam do, we have to pray 5 times a day. But surprisingly they even provide the Musholla and allow the worker to wear hijab. On the other one, said because the jobs that was given didn't really hard to do as a woman, just packing and loaded the goods.

Second, about the duration of staying. The informants in this study stayed in Japan approximately a year and an informants stay in Japan for 3 years. The 3 people said that they choose a year of staying, because they just want to know how working in Japan was and how they can improve the Language by experienced themselves. They thought that a year is enough to improve their skill in Japanese. Moreover, one person said that they preferred a year of staying Japan because it's hard for her to do religion activity there, because this informant join the religion activity regularly, it's her consideration also to do the internship. While, the man with 3 years' experience of staying Japan was 'trapped' because he didn't know that he can choose the duration of staying there. 
And about their subjective expectations, 4 informants said that they will skilled on Japanese Language after return to Indonesia and obtained they expected that certificate that they obtained through the program will be a good weapon to fight the difficulty on looking for a job in Indonesia for the graduated students. 1 person expected they would have the experience to told to her students as a professional action in her job as a teacher in sending organization (LPK).

After they returned to Indonesia as a returnee. They have additional value as an experienced Japanese-style life working. So, the Japanese Company will highly recruit this people, beside they have the basic knowledge on how the Japanese Company works and about its culture. Based on the interview, several informants said that they receiving quite high salary than the fresh graduated from the university in Indonesia used to receive as they have experienced the trainee experience in Japan.

The Experiences that they obtained after the program, surely giving the good impact on their career Indonesia. But we argue that this program was the tactically technic from Japan that it seeks on the worker with a good quality with several requirements such as the higher education, having knowledge about the language and the Japan's cultural condition to enter their labor force as a trainee, with the low wages.

The Japan's 'self-branding' known as having the good impression as a country, good perception on well and high technology producing country and having the unique on cultural (pop cultural and traditional culture) quite work and attracted those people to join the program. But, as the purpose of the program established, there are far from the reality. JITCO (Japan International Training Cooperation Organization) as the organization that maintained the training operation of this internship program, on its manual said that the purpose of this training program is to equip the trainee on knowledge, skill, professional technic that acquire in the Japan's industry and its technology. Whereas the skill that acquired from the trainee had are on the skill of their language, not on the technology that expected to be acquired. So, its indicated half of the purpose did well but on several purpose is still blurry seen.

\section{Conclusion}

Through the analysis, the macro, meso and micro level factors that indicated by push and pull factors on decision making in micro level here as an actor is inevitable. There also calculation or consideration that has to be thought by the actor to do the action. The consideration upon the purpose, the capital that they have, has an important role on migration decision making.

The Japanese Languages graduated here take the consideration on being the trainee because they want to acquired skill that they might have by join the internship program and the benefits after they returned will be highly as the labor force. But not only about the benefits, but also how they maximize their human capital and cultural capital to obtained their benefits. They did the unskilled jobs to acquired skilled on Japanese Language and experienced living in Japan as the highly capital to re-enter Indonesian field labor and get a better chance of work and life.

\section{References}

[1] N. I. of P. and S. S. R. Static Bureau of The Ministry of Internal Affair and Communications, "Japan's Population is Ageing," Static Bureau of The Ministry of Internal Affair and Communications, National Institute of Population and Social Security Research, 2018. .

[2] Statistical Data, "Japan Labor Force until 2015," Statistical Data, 2016. [Online]. Available: 
https://www.stat.go.jp/english/data/nenkan/67nenkan/1431-02.html.

[3] J. S. Coleman, "Social Capital. Megjelent: Coleman, JS: Foundations of Social Theory. 12. fejezet." Harvard University Press, Cambridge, 1990.

[4] S. Haug, "Migration networks and migration decision-making," J. Ethn. Migr. Stud., vol. 34, no. 4, pp. 585-605, 2008.

[5] K. Kaneko, “An Analysis of Japan's Popular Cultural Tourism: Constructing Japan's Self-Image as a Provider of 'Unique' Culture,” Glob. J. Hum. Soc. Sci. Sociol. Cult., vol. 13, no. 4, 2013. 